predictions about future observations. But in either case the rival hypotheses could be tested only through the sensations predicted from them, and these by construction are identical. Thus apparently the theory of probability makes no decision whatever between critical realism and critical idealism, if the latter is taken as admitting other personalities ; both are legitimate hypotheses with probability $\frac{1}{2}$, and I can see no type of evidence that could alter this. I am speaking, of course, of the definite idealism that says that the world is nothing but an invention; the indefinite idealism that merely says that it may be is the statement 'either definite idealism or realism is true', and cannot be used to deny realism. In any case it does not make the slightest practical difference which we adopt.

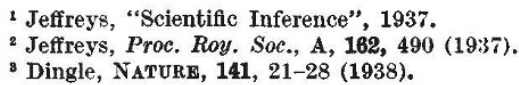

Jeffreys, "Scientific Inference", 1937.

2 Jeffreys, Proc. Roy. Soc., A, 162, 490 (1937).

${ }^{3}$ Dingle, Nature, 141, 21-28 (1938).

\title{
Cambridge Meeting of the British Association
}

$\mathrm{T}^{\mathrm{H}}$ HERE can be no doubt that the British Association, adaptable though it is to various environments, is most at home in an academic setting. This year's meeting in Cambridge ought, therefore, to be unusually happy, and the preliminary programme just issued affords prospects of this by more than one implication. Thirteen of the colleges-in addition to Emmanuel, where the secretariat will be housed-offer men the chance to return for a short space to the pleasures of college life ; Cheshunt College will be open for women, and other houses (including Girton) will accommodate both sexes. In addition to the University reception in the Senate House and Old Schools, conversaziones, pleasantly specified as 'informal', are announced in Trinity and St. John's, and the Mayor and Mayoress of Cambridge must surely be introducing a new and welcome feature into British Association programmes by inviting members to a sherry party, to be held in Emmanuel. It is to be hoped that the unusually early date of the meeting, August 17-24, dictated as it is by the convenience of the colleges and other authorities, will not dismay any of those who contemplate being present : it may be recalled in this connexion that the last Cambridge meeting, in 1904 , took place at exactly the same time, but had nevertheless an attendance of 2,789 , a figure far above the average for that period.

The presidential address, by Lord Rayleigh, will deal with "Natural Vision aided by Science", and a few lines which indicate its content may be quoted as an unusual but arresting feature in the programme. "The address," it is stated, "will show how, taking the eye as a prototype, most of the observational methods of modern science may be regarded as derived from it by successive modifications. A further part of the Address will deal with science and warfare, and will be directed to show that the relation between them is of the nature of an accidental by-product, and has in no sense been the primary goal of investigation."

The subjects of sectional presidents' addresses are announced as follows :

Section A (Mathematical and Physical Sciences) : Dr. C. G. Darwin, "Fundamentals in Physical Theory"; Section B (Chemistry): Prof. C. S. Gibson, "Recent Investigations in the Chemistry of Gold"; Section C (Geology): Prof. H. H. Swinnerton, "Development and Evolution"; Section D (Zoology) : Dr. S. W. Kemp, "The Future Development of Oceanography; Section E (Geography) : Prof. T. Griffith Taylor, "Correlations and Culture, a Study of Technique" ; Section F (Economics): Mr. R. F. Harrod, "Scope and Methods of Economics"; Section G (Engineering) : Prof. R. V. Southwell, "The Changing Outlook of Engineering Science"; Section H (Anthropology) : Prof. V. Gordon Childe, "The Orient and Europe" ; Section J (Psychology) : Dr. R. H. Thouless, "Eye and Brain as Factors in Visual Perception"; Section K (Botany): Prof. W. Stiles, "The General Physiology of the Plant Cell and its Importance for Pure and Applied Botany"; Section L (Education) : Mr. J. Sargent, "The Proper Function of Administration in Public Education"; Section M (Agriculture) : Prof. R. G. Stapledon, "Lay Farming".

Section I (Physiology) will not hold separate meetings, owing to the unfortunate clash of date between the British Association and the International Physiological Congress at Zurich. It seems strange that no mechanism to prevent such collisions has ever been devised.

The sectional programmes, even at this early stage, promise at least as diverse interest as usual. By way of examples among many subjects: Section A will deal with nuclear physics, highaltitude cosmic ray work, very low temperatures, and seismology. Section B promises a notable 
lecture-demonstration on gold films and their applications. Section C, among other subjects, will deal with the water supply of the county of London. Sections $\mathrm{D}$ and $\mathrm{K}$ will meet jointly to discuss the mechanism of evolution. Section $G$ will consider problems of road and air transport, and will devote a special period to papers by junior workers. Section $J$ will co-operate with Section $D$ on questions of sense perception and the evolution of colour and pattern, and with Section $L$ on the effect of the cinema and wireless on the life of the school child. Section L will discuss "Education for a Changing Society" in various aspects. Section M will consider agriculture in relation to national employment, soil conservation and enhancement of fertility, and crop and animal production.

The Conference of Delegates of Corresponding Societies will meet under the presidency of the Earl of Onslow, who in his address will discuss national parks, a subject to which the Association has properly given much attention. The evening discourses will be given by Dr. H. Godwin on the "History of the Fens", and by Prof. M. L. Oliphant on the "Contribution of the Electrical Engineer to Modern Physics". Of these, Dr. Godwin's discourse will be given on the Friday, thus appropriately preceding the Saturday excursions which will no doubt give many members a sight of the Fenland.

For the rest, full advantage will be taken of the exceptional opportunities offered by the various laboratories for exhibits and demonstrations, and certain special exhibits also are announced. Old scientific instruments will be shown under the auspices of the Cambridge Philosophical Society. There will be an exhibition illustrating the genetics of colour. It is proposed to have an exhibition of works of art by members of the Association-a feature, so far as records go, quite new to the programme. Members who would be willing to exhibit are asked to communicate with Mr. E. N. Willmer, St. John's College, Cambridge. Photographs taken by members of the recent scientific delegation in India will be shown. It is intended also that two lectures shall be given on the work of the delegation, of which it is hoped that one will be by Sir James Jeans, who led the delegation as president of the Indian Science Congress.

Provision for excursions is as ample as ever : the range extends from Sandringham on one hand to the Gliding Club at Dunstable and Tring Museum on the other, and opportunity will be afforded for visits to points of beauty and interest in Cambridge itself.

\section{News and Views}

\section{Prof. Max Planck, For. Mem. R.S.}

Prof. Max Planck, originator of the quantum theory and emeritus professor of theoretical physics in the University of Berlin, will celebrate his eightieth birthday on April 23. Planck's work had a singularly direct influence on the development of modern physical theory. Beginning with purely thermodynamical studies-which have been embodied in his well-known text-book on thermodynamies-he soon applied both the descriptive and the statistical methods of thermodynamics to radiation, and was successful in finding a formula for the spectral energy distribution of black-body radiation which fitted the measurements and which could be deduced on the assumption that radiation is transferred from matter in quanta of energy proportional to the frequency $v$. Successive editions of Planck's book "Wärmestrahlung" show the development and variation of the original theory, of which the underlying physical idea remained for many years a mystery to physicists, although Planck's constant $h$ was found to enter into various relations between radiation and matter, for example, in the photo-effect. It was not until Bohr explained the laws of spectral emission of atoms by a two-fold application of Planck's constant that this latter was recognized as fundamental for all kinds of atomic action.

IN all this rapid development, Planck took a prominent, if cautious, part, with the result that his publications have long been considered as classics of German physical literature. His judgment largely influenced the development of contemporary physics. When Einstein's principle of relativity showed the way out of the axiomatic and other difficulties of electrodynamics, it was Planck who took up the idea and carried it through for mechanics and thermodynamics. Although many honours have been conferred on Planck, including the Nobel Prize in Physics in 1918 and the Copley Medal of the Royal Society in 1929, they have failed to spoil his simple and unpretentious ways. Confronted with the difficulties of the monetary inflation in Germany, Planck did not mind travelling a whole night on the railway in the old fourth class, in order to get to the Alps which he loved from his youth and in which a dolomite peak bears his name as the first to have climbed it. The German Physical Society is giving a banquet in the Harnackhaus on April 22 to celebrate Planck's birthday. 